\title{
Noninvasive Prenatal Testing for Fetal Chromosomal Abnormalities Using Massively Parallel Sequencing: Clinical Experience from 7910 Korean Pregnancies
}

\author{
Seon Young Yun, Hyuk Jung Kwon, Amit Goyal, Katiyar P. Shashank, Heesu Im, Joungsu Joo, \\ Jin-Sik Bae, Min Seob Lee, Sunghoon Lee*
}

EONE-DIAGNOMICS Genome Center (EDGC), Incheon, South Korea

Email: *shlee@edgc.com

How to cite this paper: Yun, S.Y., Kwon, H.J., Goyal, A., Shashank, K.P., Im, H., Joo, J., Bae, J.-S., Lee, M.S. and Lee, S. (2018) Noninvasive Prenatal Testing for Fetal Chromosomal Abnormalities Using Massively Parallel Sequencing: Clinical Experience from 7910 Korean Pregnancies. Open Journal of Genetics, 8, 42-53.

https://doi.org/10.4236/ojgen.2018.83005

Received: June 24, 2018

Accepted: August 21, 2018

Published: August 24, 2018

Copyright (c) 2018 by authors and Scientific Research Publishing Inc. This work is licensed under the Creative Commons Attribution International License (CC BY 4.0).

http://creativecommons.org/licenses/by/4.0/ (c) (i) Open Access

\begin{abstract}
Objective: The purpose of this study is to review the clinical experience and performance of noninvasive prenatal testing (NIPT) method, using cell-free DNAto detect chromosomes 21, 18, 13, X, and Y abnormalities in over 7910 clinical samples from South Korean population. Method: Pregnant women between $1^{\text {st }}$ of November 2015 to $18^{\text {th }}$ of February 2018, with obstetric clinical findings participated in the study. NIPT was performed based on masivelly parallel sequencing with $0.3 \times$ low coverage paired-end sequencing using cell-free DNA in maternal plasma. Further invasive prenatal testing was recommended for pregnant women with positive NIPT results. Results. Of the total 7910 participants, 7890 (99.75\%) were tested for NIPT and the remaining $20(0.25 \%)$ were below the Quality Control (QC) standards. T13, T18, XXX, XXY and XYY had 100\% of sensitivity, specificity, positive predictive values (PPV) and accuracy. The overall sensitivity was $100 \%$ and specificity, PPV and accuracy of all chromosomal abnormalities with further validation were $99.92 \%, 94.25 \%$, and, 99.92\% respectively. Conclusion: Our NIPT results showed high positive predictive value for the detection of autosomal trisomies and sex chromosome aneuploidies in our sample cohort.
\end{abstract}

\section{Keywords}

Cell-Free DNA, Trisomy, Clinical Performance, Mosaicism, CPM, Fetal Abnormality, Noninvasive Prenatal Testing, NIPT

\section{Introduction}

In 2017, there were about 360,000 newborn babies in South Korea. Although the 
number of newborns is decreasing annually, the demand for NIPT test increases due to maternal aging, which is considered as common cause of chromosomal aneuploidies. Trisomy 21, also known as Down syndrome, is the most common chromosomal aneuploidy with around $0.001 \%$ occurrence rate in general population, however the risk increases up to $0.02 \%$ for women with high maternal age (above 45 years old) [1] [2] [3] [4]. The trisomy 18 (Edwards syndrome) and trisomy 13 (Patau syndrome) with estimated prevalence of $1 / 6000,1 / 16,000$, respectively, are reported to be most commonly occurring chromosomal aneuploidies. Traditional invasive methods of fetus prenatal screening, e.g. amniocentesis and chorionic villus sampling, have a high miscarriage risk as well as low detection rate of $50 \%-95 \%$ at a $5 \%$ false-positive rate. Recent technology advancement in Next Generation Sequencing (NGS) and Bioinformatics led to a novel Non-Invasive Prenatal Test (NIPT) method to analyze fetus aneuploidy using cell-free DNA (cfDNA) in the plasma of pregnant women. Although the results may vary depending on the analytical methods, many studies have reported that NIPT introduces a higher sensitivity and specificity than the conventional first trimester screening (FTS) [4] [5] [6]. The analysis uses massive parallel sequencing data and applies statistical normalization to each chromosome read count. Sequence reads are mapped to the human reference genome and used to calculate z-score after normalizing [7]. Most of the published NIPT studies rely on the $\mathrm{z}$-score calculation, which represents the quantitative variations of the chromosome of interest with the normal reference samples in dataset and the results are shown as positive or negative by checking if the z-score exceeds the predefined threshold. However, NIPT testing using the single z-score for target chromosomes such as chr21, chr18, and chr13 might be affected by unusual changes in reads that map to non-targeted chromosomes. Additionally, maternal mosaicism or copy number alteration and low fetal fraction can also cause the false NIPT results. Therefore, a proper data normalization, fetal fraction detection and better $\mathrm{z}$-score calculation algorithm is required to reduce such false results.

To overcome the above limitation in conventional methods, we developed two algorithms: Double-Z score algorithm and Multi-Z algorithm [8]. Double-Z algorithm calculates a $z$-score within a target sample, by comparing the number of GC corrected reads across all chromosomes. Double- $Z$ algorithm generates more distinguishable $z$-score by calculating again excluding chromosome 13, 18 and 21. Multi-Z algorithm in contrast shows better performance in low coverage samples. Multi-Z algorithm generates multiple $z$-scores by making the 2-demensional $z$-score matrix of each of 22 autosomal chromosomes (in 22 rows) as a reference, which are then normalized between all autosomal chromosomes. We also applied size-based cfDNA and maternal DNA fragment separation algorithm to increase the accuracy by reducing the effect of maternal mosaicism and copy number alternation [9]. Introduction of size-based fetus cfDNA enrichmentin above two algorithms showed better detection performance (close to $100 \%$ ) for autosomal as well as sex chromosome aneuploidy. 
This study is based on clinical data of 7910 NIPT test samples of South Korean population. The main objective of this study is to show the clinical performance metrics in detecting chromosomal aneuploidies as a primary screening method.

\section{Method}

\subsection{Patients and Sample Collection}

This is a prospective multicenter clinical study of NIPT cases from 107 clinical centers in Korea from November 1, 2015 to February 18, 2018. NIPT was offered to the women with high risk of aneuploidy or abnormal ultrasound findings above the age of 17 years and a minimum gestation age of 10 weeks. All pregnant women went through prenatal genetic counseling and an informed consent was conducted before blood sampling.

$10 \mathrm{~mL}$ of maternal peripheral blood was collected into a Cell-Free DNA tube (VanGenes, Xiamen, China) in clinical centers. The blood samples were delivered under room temperature to the sequencing facility. Plasma was prepared within 4 days of blood collection using a two-step centrifugation protocol. The whole-blood sample was first centrifuged at $1900 \mathrm{~g}$ for $15 \mathrm{~min}$ at $22^{\circ} \mathrm{C}$. The supernatant was transferred to sterile $1.5-\mathrm{mL}$ tubes, which were centrifuged again at $16,000 \mathrm{~g}$ for $15 \mathrm{~min}$ at $22^{\circ} \mathrm{C}$. The final supernatant was transferred to a new 5.0-mL polypropylene tube, which was stored at $-80^{\circ} \mathrm{C}$ if DNA extraction was not performed immediately. cfDNA was isolated from $2 \mathrm{~mL}$ plasma by using the QIAsymphony DSP Virus/Pathogen Kit (Qiagen, Hilden, Germany) according to the manufacturer's instructions.

\subsection{Library Preparation and DNA Sequencing}

NGS libraries were prepared from $50 \mu \mathrm{L}$ of cfDNA solution using the NEBNext ${ }^{\circledast}$ Ultra $^{\mathrm{TM}}$ II DNA Library Prep Kit and Multiplex Oligos for Illumina ${ }^{\circledR}$ according to the manufacturer's instructions (New England Biolabs, Ipswich, USA, Cat\# E7645L and E6609S). After quantification on the QIAxcel Advanced System (Qiagen, Hilden, Germany), the libraries from 70 different samples were pooled and with 75-cycle paired-end multiplex sequencing on Illumina NextSeq500 platforms (Illumina, San Diego, CA, USA).

\subsection{Quality Control}

Guidelines for quality control are provided for each process from the sample collection to the report generation. Quality-control failed blood samples(due to hemolysis) were excluded and re-sampling was done if feasible. Samples with lower amount of plasma $(<2.5 \mathrm{~mL})$ were also re-sampled. The quality parameters of the testable samples are as follows: 1) the yield should be more than $30 \mathrm{ng}, 2$ ) more than $90 \%$ reads must be over the sequencing quality threshold 30 (Q30) 3) sequenced reads must have over $41.5 \% \pm 1.5 \%$ GC content, 4) the amount of sequencing reads mapped to the human reference genome (hg19, GRCh37) must be more than $95 \%$, and 5) the minimal amount of properly paired reads must be 
at least 10 million. Subsequent analysis was performed only on the quality control criteria passed reads.

\subsection{Data Analysis and Statistical Analysis}

We used paired-end sequencing reads to identify the size distribution of fetal and maternal DNA in cell-free maternal plasma. First, paired-end reads from short cfDNA fragments of less than 150 base pairs (bp), "fetal reads", were selected to enrich cfDNAs derived from fetus cells while those from larger fragments of over $185 \mathrm{bp}$, "maternal reads" were used to enrich cfDNAs from maternal cells. Second, we calculated z-scores using GC corrected fetal and maternal reads across all chromosomes and analyzed the presence of aneuploidies of both fetal and maternal. For sex chromosomal analysis, the gender was classified using the male-specific regions of chromosome Y [10] [11] followed by the aneuploidy detection using the sex-chromosome specific $Z$ scores. The fetal fractions were obtained by regression method through the fetus-specific region and cfDNA size distribution. The precision of the results was improved through the male-specific region of the $\mathrm{Y}$ chromosome, especially for the male fetus.

\subsection{Report Delivery and Clinical Outcome Follow-up}

The NIPT clinical report is delivered within 5 - 10 calendar days from the date of sample collection. The results of the quality control, fetal fraction and the chromosome aneuploidy are provided in the clinical report. For the positive report, further confirmatory tests are recommended such as amniocentesis (AC), chorionic villus sampling (CVS) or quantitative fluorescent polymerase chain reaction (QF-PCR). These follow-up tests are used as the gold standard to calculate sensitivity (detection rate), specificity (1-False Positive Rate), positive predictive value (PPV) and 95\% CIs on the assumption of a standard normal distribution. Follow-up counseling is provided by the clinician based on the outcome of the screening and/or confirmative tests. In addition to the fetus, NIPT test can also detect chromosomal abnormalities in the mother, which are reported in the NIPT report as additional findings. The entire procedure, including all the steps described so far, is illustrated in Figure 1.

\subsection{NIPT Performance Calculation}

An indicator of the accuracy of NIPT is the sensitivity and specificity. However, an important indicator to consider when interpreting NIPT results is PPV, which is an indicator that is affected by the prevalence of the disease. We used the results of follow-up examinations to calculate the sensitivity, specificity, PPV, and 95\% confidence interval (CI) for NIPT positive results. For clinical outcome data, the sensitivity was calculated based on true positives (TP), true negatives (TN), false positives (FP), and false negatives (FN) count as [TP/(TP + $\mathrm{FN})]$, the specificity was calculated as $[\mathrm{TN} /(\mathrm{FP}+\mathrm{TN})]$, the PPV was calculated as $[(\mathrm{TP}) /(\mathrm{TP}+\mathrm{FP})]$, and the Accuracy was calculated as $[(\mathrm{TP}+\mathrm{TN}) /$ All cases $]$. 


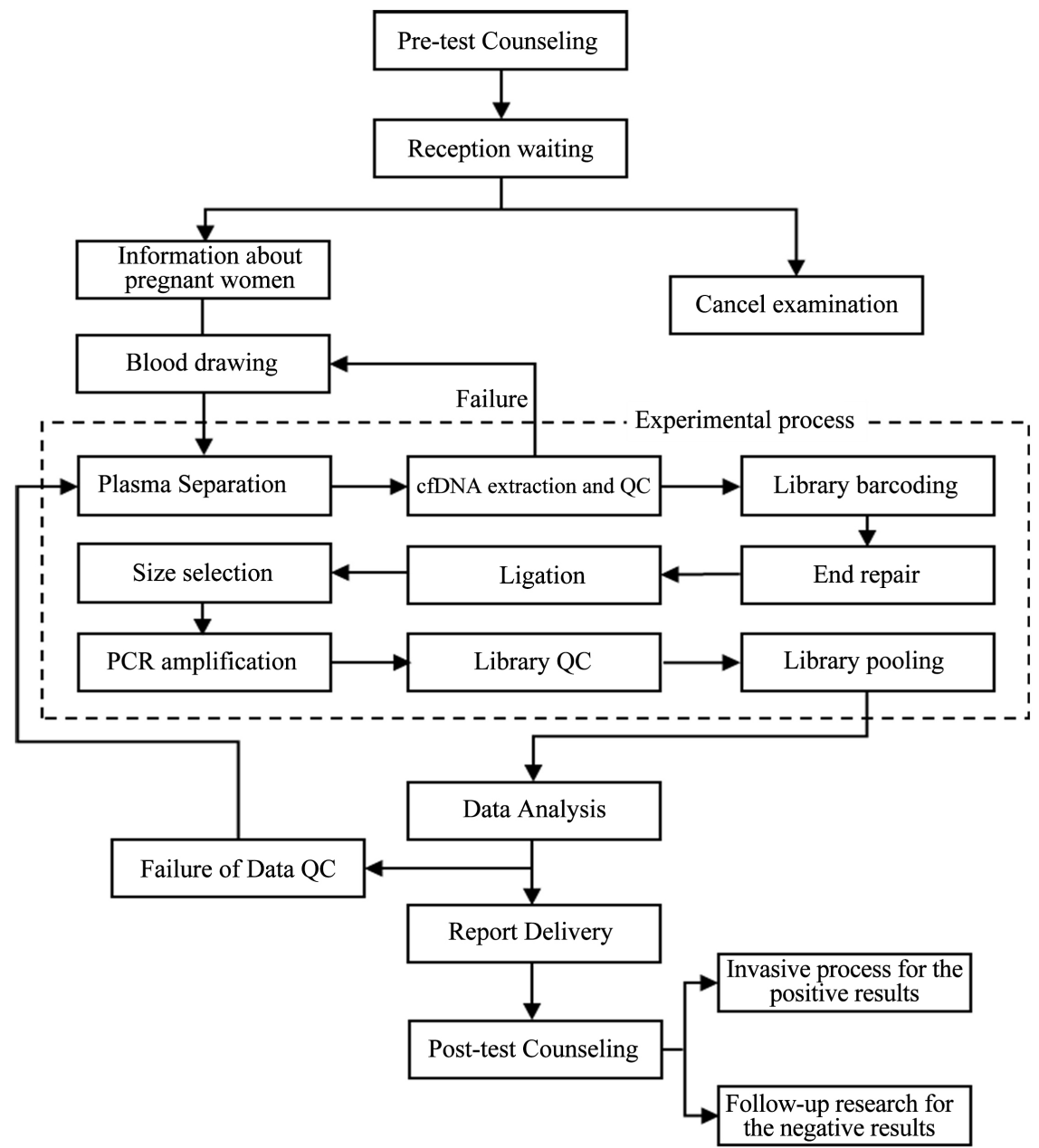

Figure 1. The entire process from sampling to delivery of NIPT result. All the positive cases were recommended for further confirmative invasive test while negative cases are monitored to ensure a complete follow-up result.

\section{Results}

\subsection{Participants}

Between November 1 of 2016 and February 18 of 2018, total 7910 pregnant women samples were collected for NIPT from 107 clinical centers in South Korea. The demographic characteristics of the pregnant women in this study are depicted in Table 1. NIPT was performed as a screening service for a total of 7910 pregnant women, including 7792 singleton and 118 twin pregnancies. The median maternal age and gestational age at the time of test was 35 (range, 16 47) years and 15 (range, 10 - 31) weeks, respectively. Of the total sample, $62.19 \%$ are samples over 35 years old and $67.5 \%$ samples were with a BMI less than 25 . The majority (99.91\%) of samples were collected during the first and second trimester. Also, 68 pregnant women in this study had a family history of chromosomal abnormalities.

Figure 2 shows the NIPT results and clinical outcomes. In this dataset, 20 samples' analysis was canceled due to improper cfDNA concentration, hemolysis, 
quality control failure, and premature gestational age. Further, a total of 64 samples failed due to low fetal fraction while the NIPT service could not provide any accurate and conclusive analysis for the 84 samples and classified as failures.

Table 1. Demographic characteristics of the study population.

\begin{tabular}{|c|c|c|}
\hline Characteristic & $\begin{array}{c}\text { Total } \\
(\mathrm{n}=7910)\end{array}$ & $\begin{array}{l}\text { NIPT positives } \\
\quad(n=183)\end{array}$ \\
\hline Maternal age (yrs) & $35(16-47)$ & $36(25-46)$ \\
\hline $16-24$ yrs (n, \%) & $144(1.82 \%)$ & $0(0.00 \%)$ \\
\hline $25-29$ yrs (n, \%) & $724(9.15 \%)$ & $8(4.37 \%)$ \\
\hline $30-34$ yrs (n, \%) & $2123(26.84 \%)$ & $45(24.59 \%)$ \\
\hline $35-40$ yrs (n, \%) & $4346(54.94 \%)$ & $97(53.01 \%)$ \\
\hline$>40$ yrs $(\mathrm{n}, \%)$ & $573(7.24 \%)$ & $33(18.03 \%)$ \\
\hline Gestational age (wks) & $15(10-31)$ & $13(10-20)$ \\
\hline First trimester (9 - 13 wks) & $3469(43.86 \%)$ & $99(54.10 \%)$ \\
\hline Second trimester (14 - 27 wks) & 4434 (56.06\%) & $84(45.90 \%)$ \\
\hline Third trimester ( $\geq 28$ wks) & $7(0.09 \%)$ & $0(0.00 \%)$ \\
\hline BMI & $22(15.1-45.8)$ & $21(15.6-34.5)$ \\
\hline Underweight $(<18.5 \mathrm{bmi})$ & $363(4.59 \%)$ & $10(5.46 \%)$ \\
\hline Normal (18.5 - 22.9 bmi) & $3661(46.28 \%)$ & $99(54.10 \%)$ \\
\hline Overweight (23 - 24.9 bmi) & $1315(16.62 \%)$ & $26(14.21 \%)$ \\
\hline Obese Class I (25 - 29.9 bmi) & $1429(18.07 \%)$ & $22(12.02 \%)$ \\
\hline Obese Class II (30 - 35 bmi) & $338(4.27 \%)$ & $5(2.73 \%)$ \\
\hline Obese Class III (>35 bmi) & $53(0.67 \%)$ & $0(0.00 \%)$ \\
\hline Unknown & $751(9.49 \%)$ & $21(11.48 \%)$ \\
\hline Singleton pregnancy & $7792(98.51 \%)$ & $179(97.81 \%)$ \\
\hline Twin pregnancy & $118(1.49 \%)$ & $4(2.19 \%)$ \\
\hline \multicolumn{3}{|l|}{ Other high-risk factors } \\
\hline 1 risk factor & $7142(90.29 \%)$ & $154(84.15 \%)$ \\
\hline Serum screening test High risk group & $2029(28.41 \%)$ & $47(30.52 \%)$ \\
\hline Ultrasound abnormal findings & $238(3.33 \%)$ & $26(16.88 \%)$ \\
\hline Advanced maternal age & $2928(41.00 \%)$ & $43(27.92 \%)$ \\
\hline Family history of aneuploidy & $68(0.95 \%)$ & $1(0.65 \%)$ \\
\hline Other & $1879(26.31 \%)$ & $37(24.03 \%)$ \\
\hline More than 2 risk factors & $734(9.28 \%)$ & $29(15.85 \%)$ \\
\hline Unknown & $34(0.43 \%)$ & $0(0.00 \%)$ \\
\hline
\end{tabular}




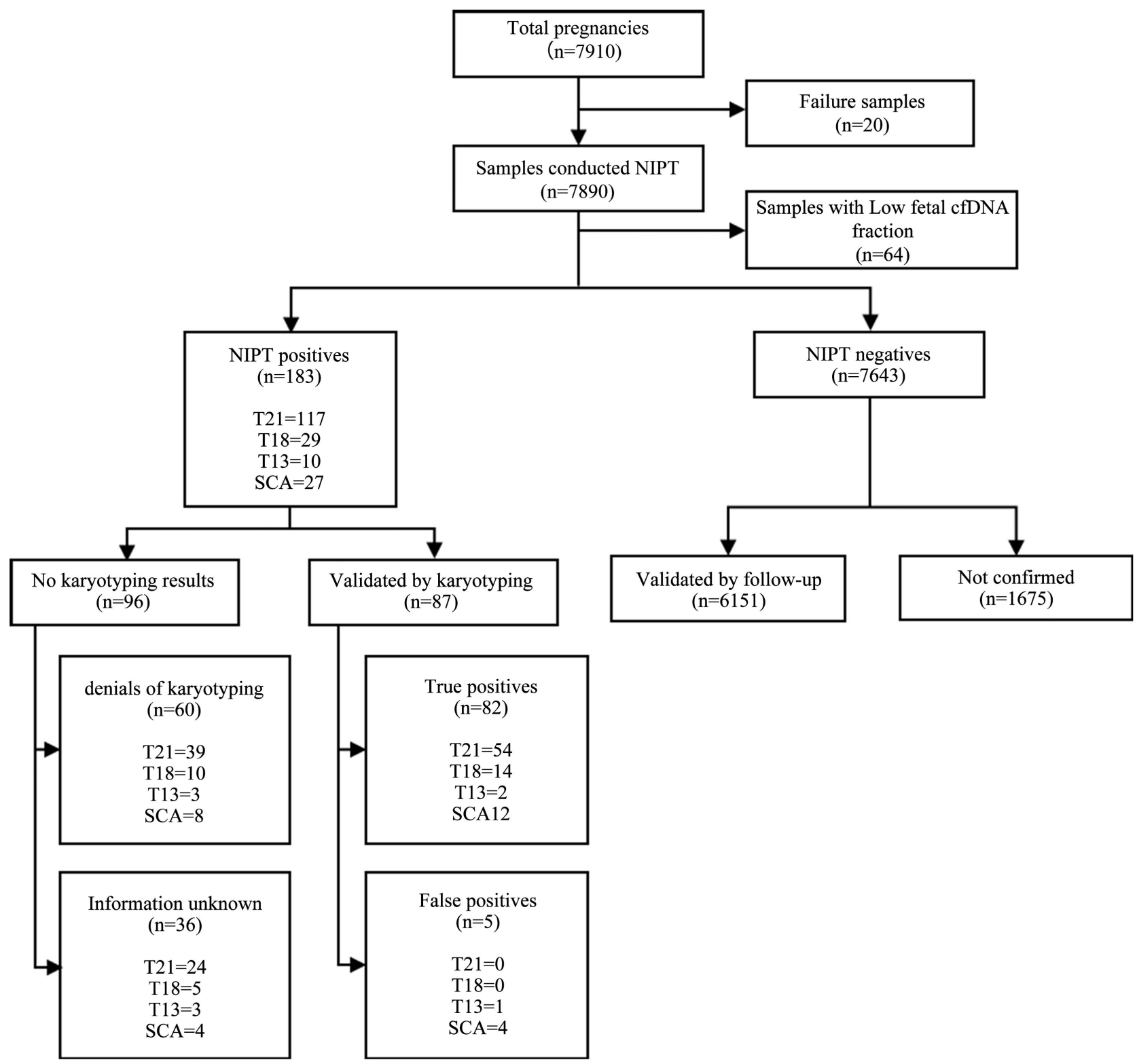

Figure 2. Summarizing study participants and NIPT results and clinical outcome. A total of 7910 pregnant women underwent NIPT in several obstetrical center. Among 7890 pregnancies, 64 pregnancies with low fetal fraction were excluded and 183 pregnancies were positive and 7643 pregnancies were negative. Only 87 of the positive samples were further analyzed and 82 of them were true positive samples.

\subsection{Follow-Up Investigation of NIPT Positive Cases}

Among the 7826 samples obtained from the NIPT results, 185 (2.36\%) were reported to have chromosomal aneuploidy and 87 of them (47.54\%) were validated by karyotyping. Of the 87 validated samples, 82 are TP and 5 are FP (Figure 2). Further analysis of the five FPs, as listed in Table 2, depicts that the false positives are caused due to the partial duplication of maternal chr21 (in case of T21) and mosaic aneuploidy of maternal chromosome or probably Confined placental mosaicism (in case of XO). However, all these 5 false-positive cases were classified as normal after performing size-based fetus and maternal cfDNA analysis. 
Several rare cases have been found in our TP cases, e.g. one T21 case (Table 2) was detected as Robertsonian translocation even though the karyotyping test had diploid, one T18 case was proven as pseudoisodicentric (psuidic) [7]. In one sample of mosaic XO, 46, X, del (Xp) was observed in 24 out of 30 cells and 46, $\mathrm{X}, \mathrm{i}(\mathrm{Xq})$ karyotype was observed in the remaining 6 cells (Table 2).

Clinical information for NIPT positive samples is shown in Table 1. The NIPT positive sets were higher in the mean maternal age and more than two risk factors as compared to the total set including NIPT negative results.

\subsection{Follow-Up Investigation of NIPT Negative Cases}

Assuming that 6151 pregnancies over 10 weeks of gestation gave a birth, no false negatives were reported at the time of writing this paper, no abnormal comments have been reported from the monthly diagnosis for the remaining unconfirmed samples.

\subsection{Clinical Performance of NIPT Results}

A total of 6238 cases including 87 NIPT positive results validated by karyotyping and 6151 NIPT negative results confirmed by insurance policy, were analyzed for sensitivity, specificity, PPV, accuracy, and incidence analysis in Table 3. There were 54 T21, 14 T18, 3 T13, and 7643 euploid cases. T18, T13, XXX, XXY and XYY had 100\% sensitivity, specificity, PPV and accuracy while T21 had 99.98\% specificity and XO had $99.94 \%$ specificity. The overall sensitivity, specificity, PPV, and accuracy of all chromosomal abnormalities were $100.00 \%$,

Table 2. Summary of clinical tracing results of false-positive and cytogenetic variant NIPT results.

\begin{tabular}{|c|c|c|c|c|c|c|}
\hline \multicolumn{7}{|c|}{ False-positive NIPT results $(\mathrm{n}=3)$} \\
\hline Results & $\begin{array}{c}M A \\
(y r s)\end{array}$ & $\begin{array}{c}G A \\
(w k s)\end{array}$ & $\begin{array}{r}B M I \\
(b m i)\end{array}$ & $\begin{array}{l}F F \\
(\%)\end{array}$ & $\begin{array}{l}\text { Cytogenetic } \\
\text { confirmation }\end{array}$ & Remark \\
\hline T13 & 37 & 11 & $\begin{array}{l}\text { Overweight } \\
(23.28)\end{array}$ & 20.7 & $46, \mathrm{XY}$ & Vanishing Twin \\
\hline $\mathrm{XO}$ & 36 & $11+3$ & $\begin{array}{l}\text { Normal } \\
(20.59)\end{array}$ & 5.6 & $46, \mathrm{XX}$ & $\begin{array}{l}\text { Family history of } \\
\text { aneuploidy }\end{array}$ \\
\hline $\mathrm{XO}$ & 35 & $17+1$ & $\begin{array}{l}\text { Normal } \\
(19.7)\end{array}$ & 9.9 & $46, \mathrm{XX}$ & \\
\hline \multicolumn{7}{|c|}{ Cytogenetic variant NIPT results $(\mathrm{n}=3)$} \\
\hline T18 & 34 & $11+5$ & $\begin{array}{c}\text { Normal } \\
(21.9)\end{array}$ & 12.4 & $\begin{array}{c}\text { 46, XY, psu idic (18) } \\
\text { (p11.31) }\end{array}$ & $\begin{array}{l}\text { Ultrasound result } \\
\text { (NT } 3.9 \mathrm{~mm})\end{array}$ \\
\hline $\mathrm{T} 21$ & 41 & 13 & Unknown & 10.2 & $\begin{array}{c}46, \mathrm{XY},+21, \operatorname{der}(21 ; 21) \\
(\mathrm{q} 10 ; \mathrm{q} 10)\end{array}$ & $\begin{array}{l}\text { Ultrasound result } \\
\text { (NT } 3.9 \mathrm{~mm})\end{array}$ \\
\hline $\mathrm{XO}$ & 37 & $16+5$ & $\begin{array}{c}\text { Overweight } \\
\quad(23.7)\end{array}$ & 7.2 & $\begin{array}{c}\text { 46, XX, del (X) (p11.1) } \\
{[24] / 46, X, \mathrm{i}(\mathrm{X})(\mathrm{q} 10)[6]}\end{array}$ & \\
\hline
\end{tabular}

Notes: MA, maternal age; yrs, years; GA, gestational age; wks, weeks; BMI, body mass index; FF, fetal fraction. 
Table 3. Overall performance of NIPT results in Korean pregnant women.

\begin{tabular}{|c|c|c|c|c|c|c|c|c|c|c|}
\hline \multicolumn{11}{|c|}{ Positive NIPT cases with confirmatory prenatal karyotype $(n=6238)$} \\
\hline Trisomy & $\begin{array}{l}T P \\
(\mathrm{n})\end{array}$ & $\begin{array}{l}F P \\
(\mathrm{n})\end{array}$ & $\begin{array}{l}F N \\
(\mathrm{n})\end{array}$ & $\begin{array}{c}\text { Sensitivity \% } \\
(95 \% \mathrm{CI})\end{array}$ & \multicolumn{2}{|c|}{$\begin{array}{c}\text { Specificity \% } \\
\text { (95\% CI) }\end{array}$} & $\begin{array}{c}P P V \% \\
(95 \% \mathrm{CI})\end{array}$ & \multicolumn{2}{|c|}{$\begin{array}{c}\text { Accuracy \% } \\
(95 \% \mathrm{CI})\end{array}$} & $\begin{array}{c}\text { Incidence \% } \\
(95 \% \mathrm{CI})\end{array}$ \\
\hline $\mathrm{T} 21$ & 54 & 1 & 0 & $\begin{array}{c}100 \\
(93.40-100)\end{array}$ & \multicolumn{2}{|c|}{$\begin{array}{c}99.98 \\
(99.91-100)\end{array}$} & $\begin{array}{c}98.18 \\
(88.38-99.74)\end{array}$ & \multicolumn{2}{|c|}{$\begin{array}{c}99.98 \\
(99.91-100)\end{array}$} & $\begin{array}{c}0.87 \\
(0.66-1.14)\end{array}$ \\
\hline T18 & 14 & 0 & 0 & $\begin{array}{c}100 \\
(76.84-100)\end{array}$ & \multicolumn{2}{|c|}{$\begin{array}{c}100 \\
(99.94-100)\end{array}$} & 100 & \multicolumn{2}{|c|}{$\begin{array}{c}100 \\
(99.94-100)\end{array}$} & $\begin{array}{c}0.22 \\
(0.12-0.38)\end{array}$ \\
\hline T13 & 2 & 0 & 0 & $\begin{array}{c}100 \\
(15.81-100)\end{array}$ & \multicolumn{2}{|c|}{$\begin{array}{c}100 \\
(99.94-100)\end{array}$} & 100 & \multicolumn{2}{|c|}{$\begin{array}{c}100 \\
(99.94-100)\end{array}$} & $\begin{array}{c}0.03 \\
(0.00-0.12)\end{array}$ \\
\hline $\mathrm{XO}$ & 6 & 4 & 0 & $\begin{array}{c}100 \\
(54.07-100)\end{array}$ & \multicolumn{2}{|c|}{$\begin{array}{c}99.94 \\
(99.84-99.98)\end{array}$} & $\begin{array}{c}60 \\
(36.03-79.98)\end{array}$ & \multicolumn{2}{|c|}{$\begin{array}{c}99.94 \\
(99.84-99.98)\end{array}$} & $\begin{array}{c}0.10 \\
(0.04-0.21)\end{array}$ \\
\hline $\mathrm{xxX}$ & 1 & 0 & 0 & $\begin{array}{c}100 \\
(2.5-100)\end{array}$ & \multicolumn{2}{|c|}{$\begin{array}{c}100 \\
(99.94-100)\end{array}$} & 100 & \multicolumn{2}{|c|}{$\begin{array}{c}100 \\
(99.94-100)\end{array}$} & $\begin{array}{c}0.02 \\
(0.00-0.09)\end{array}$ \\
\hline $\mathrm{XXY}$ & 4 & 0 & 0 & $\begin{array}{c}100 \\
(39.76-100)\end{array}$ & \multicolumn{2}{|c|}{$\begin{array}{c}100 \\
(99.94-100)\end{array}$} & $\begin{array}{c}100 \\
(39.58-100)\end{array}$ & \multicolumn{2}{|c|}{$\begin{array}{c}100 \\
(99.94-100)\end{array}$} & $\begin{array}{c}0.06 \\
(0.02-0.16)\end{array}$ \\
\hline $\mathrm{XYY}$ & 1 & 0 & 0 & $\begin{array}{c}100 \\
(2.5-100)\end{array}$ & \multicolumn{2}{|c|}{$\begin{array}{c}100 \\
(99.94-100)\end{array}$} & 100 & \multicolumn{2}{|c|}{$\begin{array}{c}100 \\
(99.94-100)\end{array}$} & $\begin{array}{c}0.02 \\
(0.00-0.09)\end{array}$ \\
\hline Total & 82 & 5 & 0 & $\begin{array}{c}100 \\
(95.6-100)\end{array}$ & \multicolumn{2}{|c|}{$\begin{array}{c}99.92 \\
(99.81-99.97)\end{array}$} & $\begin{array}{c}94.25 \\
(87.23-97.52)\end{array}$ & \multicolumn{2}{|c|}{$\begin{array}{c}99.92 \\
(99.81-99.97)\end{array}$} & $\begin{array}{c}1.31 \\
(1.05-1.63)\end{array}$ \\
\hline \multicolumn{11}{|c|}{ All positive NIPT cases $(\mathrm{n}=6238)$} \\
\hline $\mathrm{T} 21$ & 117 & 1 & 0 & $\begin{array}{c}100 \\
(96.90-100)\end{array}$ & \multicolumn{2}{|c|}{$\begin{array}{c}99.99 \\
(99.93-100)\end{array}$} & $\begin{array}{c}99.15 \\
(94.28-99.88)\end{array}$ & \multicolumn{2}{|c|}{$\begin{array}{c}99.99 \\
(99.93-100)\end{array}$} & $\begin{array}{c}1.50 \\
(1.24-1.79)\end{array}$ \\
\hline $\mathrm{T} 18$ & 29 & 0 & 0 & $\begin{array}{c}100 \\
(88.06-100)\end{array}$ & \multicolumn{2}{|c|}{$\begin{array}{c}100 \\
(99.95-100)\end{array}$} & 100 & \multicolumn{2}{|c|}{$\begin{array}{c}100 \\
(99.95-100)\end{array}$} & $\begin{array}{c}0.37 \\
(0.25-0.54)\end{array}$ \\
\hline $\mathrm{T} 13$ & 9 & 0 & 0 & $\begin{array}{c}100 \\
(66.37-100)\end{array}$ & \multicolumn{2}{|c|}{$\begin{array}{c}100 \\
(99.95-100)\end{array}$} & 100 & \multicolumn{2}{|c|}{$\begin{array}{c}100 \\
(99.95-100)\end{array}$} & $\begin{array}{c}0.12 \\
(0.05-0.22)\end{array}$ \\
\hline XO & 12 & 4 & 0 & $\begin{array}{c}100 \\
(73.54-100)\end{array}$ & \multicolumn{2}{|c|}{$\begin{array}{c}99.95 \\
(99.87-99.99)\end{array}$} & $\begin{array}{c}75 \\
(52.97-88.88)\end{array}$ & \multicolumn{2}{|c|}{$\begin{array}{c}99.95 \\
(99.87-99.99)\end{array}$} & $\begin{array}{c}0.15 \\
(0.08-0.27)\end{array}$ \\
\hline $\mathrm{xXX}$ & 5 & 0 & 0 & $\begin{array}{c}100 \\
(47.82-100)\end{array}$ & \multicolumn{2}{|c|}{$\begin{array}{c}100 \\
(99.95-100)\end{array}$} & 100 & \multicolumn{2}{|c|}{$\begin{array}{c}100 \\
(99.95-100)\end{array}$} & $\begin{array}{c}0.06 \\
(0.02-0.15)\end{array}$ \\
\hline XXY & 6 & 0 & 0 & $\begin{array}{c}100 \\
(54.07-100)\end{array}$ & \multicolumn{2}{|c|}{$\begin{array}{c}100 \\
(99.95-100)\end{array}$} & 100 & \multicolumn{2}{|c|}{$\begin{array}{c}100 \\
(99.95-100)\end{array}$} & $\begin{array}{c}0.08 \\
(0.03-0.17)\end{array}$ \\
\hline $\mathrm{XYY}$ & 2 & 0 & 0 & $\begin{array}{c}100 \\
(15.81-100)\end{array}$ & $\begin{array}{r}10 \\
(99.95\end{array}$ & $\begin{array}{l}0 \\
-100)\end{array}$ & 100 & $\begin{array}{r}10 \\
(99.95\end{array}$ & 100) & $\begin{array}{c}0.03 \\
(0.00-0.09)\end{array}$ \\
\hline Total & 180 & 5 & 0 & $\begin{array}{c}100 \\
(97.97-100)\end{array}$ & $\begin{array}{r}99 . \\
(99.85\end{array}$ & $\begin{array}{l}93 \\
99.98)\end{array}$ & $\begin{array}{c}97.30 \\
(93.75-98.86)\end{array}$ & $\begin{array}{r}99 . \\
(99.85-\end{array}$ & $\begin{array}{l}4 \\
9.98)\end{array}$ & $\begin{array}{c}2.30 \\
(1.98-2.66)\end{array}$ \\
\hline $\begin{array}{l}\text { Theoret } \\
\text { Boundaries }\end{array}$ & $\begin{array}{l}\text { al PPV } \\
\text { ondition }\end{array}$ & & $\begin{array}{l}\text { isomy } 21 \\
\%(\mathrm{n}))\end{array}$ & $\begin{array}{l}\text { Trisomy } 18 \\
(\%(\mathrm{n}))\end{array}$ & $\begin{array}{l}\text { Trisomy } 13 \\
\text { (\% (n)) }\end{array}$ & $\begin{array}{c}X O \\
(\%(\mathrm{n}))\end{array}$ & $\begin{array}{c}X X X \\
(\%(\mathrm{n}))\end{array}$ & $\begin{array}{c}X X Y \\
(\%(\mathrm{n}))\end{array}$ & $\begin{array}{c}X Y Y \\
(\%(\mathrm{n}))\end{array}$ & $\begin{array}{c}\text { Total } \\
(\%(\mathrm{n}))\end{array}$ \\
\hline $\begin{array}{l}\text { Lower b } \\
\text { All unconfi } \\
\text { consider }\end{array}$ & $\begin{array}{l}\text { Indary } \\
\text { ned cases } \\
\text { l as FP }\end{array}$ & 46.1 & $5(54 / 117)$ & $48.28(14 / 29)$ & $\begin{array}{c}22 \\
(2 / 9)\end{array}$ & $\begin{array}{c}50 \\
(6 / 12)\end{array}$ & $\begin{array}{c}20 \\
(1 / 5)\end{array}$ & $66.67(4 / 6)$ & $\begin{array}{c}50 \\
(1 / 2)\end{array}$ & $45.56(82 / 180)$ \\
\hline Upper b & indary & & & & & & & & & \\
\hline $\begin{array}{r}\text { All unconfi } \\
\text { consider }\end{array}$ & $\begin{array}{l}\text { ned cases } \\
\text { as TP }\end{array}$ & 99.1 & $5(116 / 117)$ & $100(29 / 29)$ & $90(9 / 9)$ & $66.7(8 / 12)$ & $\begin{array}{l}100 \\
(5 / 5)\end{array}$ & $\begin{array}{l}100 \\
(6 / 6)\end{array}$ & $\begin{array}{l}100 \\
(2 / 2)\end{array}$ & $97.22(175 / 180)$ \\
\hline
\end{tabular}

Notes: CI, confidence interval; NIPT, noninvasive prenatal testing; TP, true positive; FP, false positive; FN, false negative; PPV, positive predictive value. 
99.92\%, 94.25\%, and $99.92 \%$ respectively. The three most frequent incidents were $\mathrm{T} 21, \mathrm{~T} 18$, and $\mathrm{XO}$ in that order.

Assuming that all positive results are $\mathrm{TP}$, the overall specificity, sensitivity, PPV, and accuracy of all chromosomal abnormalities were 99.93\%, $100.00 \%$, $97.30 \%$, and $99.94 \%$, respectively.

A theoretical PPV was also calculated under the two boundary conditions that all invalidated NIPT positive cases were either assumed to be a TPs or an FPs (Table 3).

This provided the range of PPV for T21, T18, T13, XO, XXX, XXY, and XYY as $46 \%-100 \%, 48 \%-100 \%, 30 \%-90 \%, 50 \%-85 \%, 20 \%-100 \%, 66 \%-100 \%$ and $50 \%-100 \%$, respectively.

\section{Discussion}

\subsection{Summary}

This study summarizes the demography result of the clinical use of NIPT during Nov. 2015 to Feb. 2018 in South Korea. Among 7910 patient samples, 98.9\% (7826 of 7910) were analyzed successfully while $0.3 \%$ (20 of 7910) failed by QC thresholds and $0.8 \%$ (64 of 7910) failed due to low fetal fraction. At analysis level, inconclusive or failed reports were generated mostly due to the low fetal fraction and the higher sequencing bias.

In our patient cohort, we saw a positive correlation between maternal age and the risk probability. The risk for aneuploidy starts to increase at the early 40 s and the highest risk samples are in the oldest pregnancy age group.

The performance of NIPT in detecting autosomal trisomy and sex chromosome aneuploidy was compared in Table 3. Of the 7643 negative cases, 6151 samples are considered to be true negative since they have already passed their gestation period till the time of manuscript preparation and no adverse report has been found in follow-up. The lack of karyotyping confirmation of all positive results limits the generation of sufficient performance statistics.

The adequate proportion of fetus originated fragments in maternal plasma is the key factor to make a reliable analysis result, and an approximately minimum $4 \%$ fetus fraction is required for accurate analysis [12]. In our study, fetal fraction decreased with increasing maternal weight, and more than $56.25 \%$ of samples with lower fetal fraction had a Body Mass Index (BMI) of more than 23.0. Accurate determination of fetal fraction is very important for NIPT screening test as it helps the clinician to make an informed decision. Identification of the FF for the male fetus is easier and more accurate as the algorithm can extract the male-specific chromosome Y cfDNA from the sample and calculate the normalized value to predict the FF. In this study, a correlation study between the FF values obtained both from the chromosome Y-based FF and fragment size based linear regression algorithm was performed, which revealed a high $(0.85) r^{2}$ coefficient of correlation. A high coefficient of correlation is significant as we can determine the FF of female fetus using the fragment size based linear regression 
algorithm. However, it is necessary to improve the accuracy of the FF detection to make it accurate, which will be the main area of focus in our future studies.

In the case of Turner syndrome, the false-positive rate can be high due to the maternal XO mosaicism or loss of maternal X chromosome by aging. In our study, we could observe some samples have the loss of $\mathrm{X}$ chromosome in maternal DNA. We applied cfDNA size separation method to reduce the false decision rate by distinguishing fetal $\mathrm{X}$ monosomy from maternal mosaic aneuploidy.

\subsection{Limitations of Study}

Among 183 patients, we did not receive karyotyping results for 96 samples, of which 60 participants refused for karyotyping while no follow-up information can be obtained for the remaining 36 cases. Many NIPT algorithms have false negative results for samples with low fetal fraction, so if we have a high z-score in the negative case with a strong fetus trisomy signal, we report it as "suspected" to confirm using the karyotyping. Since the maternal mosaic aneuploidy as well as the low fetal fraction may affect the overall result, karyotyping confirmation is essential for all the positive and suspected cases.

\section{Conclusion}

This study reports a high statistical confidence with the improved method of NIPT testing. The relatively high cost of NIPT and the absence of reimbursement in South Korea are main drawbacks for pregnant women. It is important that NIPT should be used effectively and ethically to be an ultimate first tier screening service. In clinics, patients should be given precise information about the limitations of NIPT testing, and the appropriate genetic counseling is needed. At the same time, NIPT service providers must continually improve experimental methods and algorithms to reduce the probability of false positives and false negatives. In addition, it is crucial that all positives cases must be confirmed by fetal karyotyping before the termination of pregnancy.

\section{Conflicts of Interest}

The authors declare no conflicts of interest regarding the publication of this paper.

\section{References}

[1] Savva, G.M., Morris, J.K., Mutton, D.E. and Alberman, E. (2006) Maternal Age-Specific Fetal Loss Rates in Down Syndrome Pregnancies. Prenatal Diagnosis, 26, 499-504. https://doi.org/10.1002/pd.1443

[2] Morris, J.K., Mutton, D.E. and Alberman, E. (2002) Revised Estimates of the Maternal Age Specific Live Birth Prevalence of Down's Syndrome. Journal of Medical Screening, 9, 2-6. https://doi.org/10.1136/jms.9.1.2

[3] Haddow, J.E. (1990) Prenatal Screening for Open Neural Tube Defects, Down's Syndrome, and Other Major Fetal Disorders. Seminars in Perinatology, 14, 488-503.

[4] Fairbrother, G., Johnson, S., Musci, T.J. and Song, K. (2013) Clinical Experience of 
Noninvasive Prenatal Testing with Cell-Free DNA for Fetal Trisomies 21, 18, and 13, in a General Screening Population. Prenatal Diagnosis, 33, 580-583. https://doi.org/10.1002/pd.4092

[5] Manotaya, S., Xu, H., et al. (016) Clinical Experience from Thailand: Noninvasive Prenatal Testing as Screening Tests for Trisomies 21, 18 and 13 in 4736 Pregnancies. Prenatal Diagnosis, 36, 224-231. https://doi.org/10.1002/pd.4775

[6] Taneja, P.A., Snyder, H.L., et al. (2015) Noninvasive Prenatal Testing in the General Obstetric Population: Clinical Performance and Counseling Considerations in over 35000 Cases. Prenatal Diagnosis, 36, 237-243. https://doi.org/10.1002/pd.4766

[7] Fan, H.C., Blumenfeld, Y.J., Chitkara, U., Hudgins, L. and Quake, S.R. (2008) Noninvasive Diagnosis of Fetal Aneuploidy by Shotgun Sequencing DNA from Maternal Blood. Proceedings of the National Academy of Sciences of the United States of America, 105, 16266-16271. https://doi.org/10.1073/pnas.0808319105

[8] Kwon, H.J., Goyal, A., et al. (2017) Multiple z-Score Based Method for Noninvasive Prenatal Test Using Cell-Free DNA in Maternal Plasma. Open Journal of Genetics, 7, 1-8. https://doi.org/10.4236/ojgen.2017.71001

[9] Chan, K.C., Zhang, J., Hui, A.B., Wong, N., Lau, T.K., Leung, T.N., Lo, K.W., Huang, D.W. and Lo, Y.M. (2004) Size Distributions of Maternal and Fetal DNA in Maternalplasma. Clinical Chemistry, 50, 88-92. https://doi.org/10.1373/clinchem.2003.024893

[10] Mangs, A.H. and Morris, B.J. (2007) The Human Pseudoautosomal Region (PAR): Origin, Function and Future. Current Genomics, 8, 129-136.

https://doi.org/10.2174/138920207780368141

[11] Skaletsky, H., Kuroda-Kawaguchi, T., Minx, P.J., Cordum, H.S., Hillier, L., Brown, L.G., et al. (2003) The Male-Specific Region of the Human Y Chromosome Is a Mosaic of Discrete Sequence Classes. Nature, 423, 825-837. https://doi.org/10.1038/nature01722

[12] Wang, E., Batey, A., Struble, C., Musci, T., Song, K. and Oliphant, A. (2013) Gestational Age and Maternal Weight Effects on Fetal Cell-Free DNA in Maternal Plasma. Prenatal Diagnosis, 33, 662-666. 